\title{
Medico - Ethnobotanical Inventory (Liver and Gallbladder Ducts Illnesses) of Nakhchivan AR, Azerbaijan
}

\section{Sayyara Ibadullayeva1 , Hilal Gasimov², Melahat Gahramanova, Peymana Zulfugarova1, Leman Novruzova²}

\author{
${ }^{1}$ Institute of Botany of the Azerbaijan National Academy of Sciences, AZ1004, 40-Badamdar Shosse, Baku, \\ Azerbaijan \\ ${ }^{2}$ Naxcivan State University, Azerbaijan \\ ${ }^{3}$ Nargiz-Medical Clinic, Azerbaijan
}

\begin{abstract}
Wide explanation on biomorphological, eco-biological and usage perispectives of herbs used in wild flora for liver and gallbladder ducts illnesse of azerbaijan people have been given in the article. At the same time, spreading area of the species, synonims, gathering period, national, traditional and scientific medicine, chemical compositions, pharmological influences and treatment directions are intoduced.
\end{abstract}

Keywords: Traditional Medicine, Ethnobotany, Herbs, Phytoteraphy, Liver And Gallbladder Ducts İllnesses

\begin{abstract}
Introduction
Throught the history, living organisms have been always in investigation, so living creatures used from nature mutually. According to historical data, 20 thausand year BCE people lived in caves had learnt to use plants as medicine and food, tried to distinguesh between harmfull and usefull plants. After people started their agricultural activities, their knowlegde about plants had been increased. It is known that people used agricultural plants in 60002000 BCE. Description of plants, their register, plant systematics had been learnt by Chinise, Indian and Egyption scientist (2000-3000 BCE) (Abu Ibn Sina; Nuh Afandi, hand writings, Hehbullayev 1991). Ancient Greek Scientists by giving firts classification of plant world, had founded the beginning of plant classification. By the learning all these, usefull properties of plants were discovered and and herbs were used in treatment of different illnesses (Khalilov 1999; Alekperli 2001).
\end{abstract}

Treated preperties of a number of plant and fruit, their usage in tradition medicine, treatment methods are known by people in Azerbaijan. These treatment methods has not lost its importance in the scientific technical century. Even Scientific medicine today admits its important. As it is known, most of the plants and fruits that involve Azerbaijan flora have medical importance and people used in treatment of some or another illnesses. A number of investigations have been carried out by Azerbaijani scientists (Ibadullayeva et al, 2007; 2010; 2011; 2012; 2014; 2015) and given information about treatment not only with plants but also with balm and ephir oil [Ibadullayeva et al., 2007; 2013; 2015].

Azerbaijan ethnobiology has a long history and we aim to develop this area and investigate wild flora.

\section{Materials and methods}

Classic and current methods have been used while studying bioecological properties of the wild herbs [Krylovaet.al., 1971; Zayko et.al., 2007]. The lifestyles of the herbs have been determined [The Azerbaijan flora, 1950-1961] and their use areas were investigated.

The data containing in monographs, transactions, dissertations, articles of various authors and archival materials concerning to botanical researches have been used in the research [Grossheym, 1936; Prilipko, 1965; Damirov, 1970; Turova et.al.,1984; Sokolov, 2000; Ethnobotany: Integrating Biology and Traditional ..., 2008; Ibadullayeva et. al., 2007; 2013; 2015].

The basic method of study of the material was the inquiry method on the D.M.Cotton's method [Cotton, 
1996]. At drawing up of questions G.F.Chursin's Program on data acquisition of folk medicine has been used [Chursin, 1929]. The ethnobotanical research methods as: the Wild ethnography; the Observation; the Survey; theQuestionnaire design; the Interview; the Balances method; the Comparative method; the Component analysis et.al. were implemented [Guber, 2001; Martin, 2001]. Technical writing devices as: a dictating machine, a motionpicture camera and a video recorder often were used in the observations.

\section{Experimental part}

Medical plants, fruit-berry tree and bushes that used in traditional medicine are known in Azerbaijan flora. A variety of diseases are cured through these kinds of plants. Phytotherapy is widely used in modern medicine. Medicine that is made of plants never threatens life. It is especially given information about herbs that are used in treatment of liver and other diseases in the article. These are followings.

Rosa canina L. consists of thorned bushes. Leaves are alternate, elliptical or obovate and sharp toothed. Flowers are large - up to $5 \mathrm{~cm}$ and are situated at the end of the stem transversely. Petals and sepals are 5 and consist of oblong carolla. It has a number of stamen and pistils. Fruit is pulpy and consists of jagged rose hips with inside hairy seeds. It ripens in August -September and stays till winter.

Chemical structure: Fruit include abundant of vitamins, ascorbic acids, philloxynon and pigments (rubixanthin, lycopene), fermium, calcium, mangan, magnesium, phosphor, microelements, riboflavin, provitamin A, vitamin K,P, E and carotin. It includes 2,5-5,5\% vitamin C, 9,8mq\% carotin, $14 \%$ pectin substances, $1,9 \%$ lemon acid, 23,9\% general sugar, $18,6 \%$ invert sugar, 5\% sakharoza, $8,9 \%$ pentoza. Seeds include oil, carotin and vitamin E. Ascorbin acid $(1-1,5 \%)$ is observed in the leaves as well. Stem, leaves and roots consists of substance $(80 \%)$, oil mixtures $1 \%$, organic substances $0,5 \%$, mineral substances $0,5 \%$.

Its fresh fruit is used to prepare syrup (Sirupus fructus Rosae), extact and vitamin mixtures (Cholosasum). The fruit of the plant is successfully used for cholesistit and hepatit.

- it needs to keep dog rose seeds in $250 \mathrm{ml}$ cold boiled water for 30 minutes then to heat until it boils and wait for 5-10 minutes. It is possible to take it with a spoon of honey or lemon juice 2-3 times a day. - 2 spoons of the fruit infused (it is better to infuse in a thermos ) in 2 glasses of water for 25 minutes may be taken 3 times a day in hot state $20-40$ minutes before meal.

From ancient times, this plant is used as a medicine in a number of disaeses. According to its rich compound dog rose has a great deal of benefit
(Cholosasum). So, it includes A, B1, B2, P, K and C vitamins, protein, minerals, bases, maqgnesium, calsium and phosphorius ions. Dog rose increases the immun system, prevents inflammatory process and helps common cold. It calms down nerve system, decreases the risk of kidney and gallbladderstones; takes stomachache, assists to clean intestines and beneficial for coronary heart diseases; increases appetite and decreases blood pressure and normalizes metabolism; it has diuretic properties .

-in order to prepare dog rose tea 2 spoons of the fruit is chopped and $250 \mathrm{ml}$ hot water is added and left for 10 minutes.

- it possible to use dog rose in order to lose weight: 3 spoons of fruit is added into a liter hot water and left for 12 hours.

It must be taken 30-40 minutes before meal 3 times a day during forthnight .

- 3 spoons of dog rose fruit and 6 spoons of maize stigmata must be infused (not to boil) in a half liter hot water and left for 12 hours and 100 gram must be drunk before meal for 3 months.

Ribes nigrum L - shrubs, and in 1-2 $\mathrm{m}$ height, the stem is straight and branching. Lower branches are almost always lies on the ground. The stem is darkgray or reddish-brown, the young bark is yellowishgray color. The leaves are alternate, stalk, up to $10 \mathrm{~cm}$ in length, heart shaped, the upper side of leaves is smooth, matte, while the down is vascular and hairy with golden spots. Flowers are 5-12 units, carolla consists of 5-petals, hanging brushed, is $5-8 \mathrm{~cm}$.

Chemical composition: the composition of fruits is (vitamin C (400-570 mg /\%), B, P vitamins, A provitamin, organic acid (citric and apple acid), sugar (glucose, fructose), glycosides, flavonoids, pectins, antocionids (cyanides delphinidin) and nitrogen. Mineral substances (mg/\%): Sodium-32, potassium372 , calcium-36, manganese-35, iron-1, phosphorus33. Buds consists of $175 \mathrm{mg} / \%, 450 \mathrm{mg}$ button $1 \%$, flowers and $270 \mathrm{mg} / \%$, and other parts the amount of ascorbic acid $470 \mathrm{mg} / \% \mathrm{~s}$.

The effect: has a diuretic effect, removes salts from the body, and increases protection ability of a liver. In particular, it is useful in the liver virus hepatitis, diabetes and anemia.

Black currants have very rich chemical composition. Mostly, rich in vitamin C. Therefore, the composition of berries are full of with antioxidants. Slows down the aging process of the body, the body is restored, and protects the body from poisons, toxins and free radicals. Black currant has a very positive effect on the immune system. This berry is very important for children, older people. As well as the composition of Group B vitamins, vitamin K, folic and pantothenic acids, black currants is rich with iron. It is very useful for people suffering from anemia. Moreover, there is another element potassium. Potassium helps the body 
to release excess fluid and salt, and as a result, improves the condition of people with cardiovascular and renal diseases. It is beneficial for the treatment and prevention of atherosclerosis. Increases appetite, improves exchange processes, lowers blood sugar. Therefore, berries can be used successfully in the diet in order to lose weight. Black currant has inflammatory, anti-rheumatic and antiseptic properties. It is useful for capillaries and veins and improves their elasticity. During bronchitis is very good and has anti-inflammatory effect of blackcurrant juice. For this reason, leaves are added to a variety of grass by doctor-phytotherapevts (5, p13-17).

Vesc Fragaria L. is perennial grass with creeping stems, plant height is $10 \mathrm{~cm}$. leaves are long stalked, leaves are sophisticated with rounded edges and large toothed. Flowers up to $2 \mathrm{~cm}$ in diameter, thich haired, 5 membered flowers collected from the group of flowers. Fruit is nut and has pulpy carolla. Flowering begins in late May and June-July, the fruit grows. Has rounded fruit, yellowish-white color.

Chemical composition: fruit contains vitamin C (50mg\%), carotenoids (5mq\%), B group vitamins, folic acid, sugar $15 \%$, apple, lemon, salicylic acid, a small amount of vaccine ingredients, essential oils, pectins, anthocyanins compounds ( 3 galactose pellarqonid and 3 glycoside cyanides), iron salts, phosphorus, cobalt, manganese, and there is an enormous amount of potassium. Many phenolic compounds and flavonoids found in cultivated types. The leaves contain vitamin C (120-200 mg\%), flavonoids (quercetin derivatives), carotenoids, cumarins, essential oil and vaccination $(9 \%)$. The fruit are full of with polivitamins. The leaves of diuretic, and to reduce the nitrogen in blood.

Usage abd intake method - the fruit is a valuable nutrient and medicinal plant.

Pink colored and fragrant strawberries are very useful fruit. Strawberries have plenty of iron and phosphorus ions. Moreover, C, B, and vitamin K. Strawberry reduces amount of cholestrine in the vein and eliminates blockage. strawberry that is a very good antioxidant increases immune system and regulates digestive system; eliminates intestive worms, it is diuretic and removes harmful substances in the body, strengthens the gum, decreases temperature and reduces stress; has a positive effect on healing rheumatism and liver diseases; moistures, freshens the skin. Leaves, in well-drained condition, can be used as a tea. Strawberry can effect on digestine if it is eaten in hungry state. Strawberry mixed with milk can be used for cleaning; can be consumed ascompot and jam; fresh and dried leaves and fruits have a diuretic and choleretic effect, the removal of salts in the body, for gout, artpoz, arthritis and rheumatic diseases is very effective; is useful for liver (viral hepatitis), diabetes and anemia hypochromic as well. It is considered indispensable medicinal plants in treatment of kidney diseases.

Zea mays $L$. annual agricultural plant grown. The height of the body up to $3 \mathrm{~m}$ in width and $3 \mathrm{~cm}$, nonbranched, lower part of the plant is stem. has a fringed root system, leaves shifts, long, linear, folded in the upper part and lower part is bare. Male flowers are broomed formed, female flowers with a lot of leg, is located between the leaves.

Chemical composition: Body and silks contain vitamin $\mathrm{K}$, pantothenic and ascorbic acid, carotenoids, steorid, saponin and oils. Silks have carotenoids, K, B1, B2, C, D, E vitamins, glycosides $(1.2 \%)$, oil $(2.5 \%)$, the etheric items $(0.2 \%)$, saponins $(3.2 \%)$, gum $(3.8 \%)$, inozit, alkaloids $(0.05 \%)$, sitosterol, cryptosantine, stiqmasterol, alkaloids, resins $(2.7 \%)$, sugar and bitter substances.

Usage and acceptance procedure: cholagogue, diuretic, normalize the metabolism and blood clotting process, liver disease, especially effective in gallbladder stones; is used for the trauma created by kidney stones - nephritis, diabetes and other diseases; as blood stooper substance in Hipoprotrombinea in different types of bleeding. Cholecystitis, cholangitis, heratit is determined in different bleeding processes. In particular, for chronic liver disease infused maize silks should be taken for a long time. This removes excess fluid in the body and regulates metabolism. Maize silks effect on the nerve system sedatively; is defined as a metabolism activator and appetite decreasing drug. Corn oil (daily dose 50-70 gr) decreases the amount of cholesterol in the blood and is determined for treatment of atherosclerosis. At the same time, it is effective for the treatment of skin diseases; eliminates kidney stone and gall bladder stone pain. Glutamine acid in its compositionis indispensible in the treatment of depression, epilepiya, progressive dystrophy and polimielit. Maize silk have been used in traditional and scientific medicine since ancient times. In the treatment of many diseases, inflammatory diseases of the kidney and urinary tract, gastritis, obesity, tuberculosis, diabetes, hypertension, skin diseases, varicose veins, sterility, potency weakness, insomnia, nerve disorders, atherosclerosis and effective natural cancer prevention maize is an effective and natural mean. One of the main benefits of maize silk is a diuretic and choleretic properties. It improves the flow of bile. Maize silk has antibacterial and antiinflammatory properties so, it eliminates pain and spazms of kidney disaeses. By regularly usage of maize silk regulates blood sugar, as well as the low level of cholesterin; is one of the best natural ways to prevent stress; eliminates nerve tension, the mental and physical fatigue and provides normal sleeping. In Obesity, kidney and urinary tract diseases maize silk is made in the following methods:

- 5 tablespoons of maize silk in $400 \mathrm{ml}$ of water is boiled on a low heat for 30 minutes; waited for 3 
hours. After this period, is filtered and is taken 3 times per day, each $30 \mathrm{ml}$ after meal.

- against obesity maize silk infusing is taken every 3 hours $50 \mathrm{ml}$ to accept and maize silk is not recommended for skinni people.

- tablespoons maize silk is infused in 2 cups of boiling water within 30 minutes, 3 times a day 30 minutes before meals (The daily dose) should be taken. extract from the plant especially from its silk has diuretic effect. Contains linolin acid (vitamin F) reduces the amount of cholesterol in the body and helps the expulsion of lipids. Phytosterol has Antixelerotic effects. Vitamin E weakens protein metabolism, prevents the accumulation of cholesterol in cappilliars.

Coriandrum sativum L. annual grass plant, including up to $70 \mathrm{~cm}$ in height, and has stem. Its stem is bare, thin and hollowed. Leaves are long and toothedi, the lower part of the stem with a short stalk, twofeathered. The upper leaves are sitting down, feathered, divided into 2-3 parts, linear. Flower group is complex umbrella, the umbrella is a 3-leafed. Flowers are small, receptacle is 5 based, fruits are toothed, white or pink flowers carolla.

Chemical composition: the composition of the plant cocsists of essential oil (0.2\%), sitral (62\%), sitronellal, heraniol and linoleic items. In addition, B1, B2, C vitamins, various organic acids, cumarins and flavonoids are found. A key component of the composition of the essential oil of lemon leaves, which are odorous substances sitral and sitronellal.

Usage and acceptance procedure: is used as a component of mixtures against hemorrhoids gastrointestinal, bile; Facilitates digestion, has analgesic effect (particularly headache); is particularly used in liver diseases (viral hepatitis); Eliminates brain fatigue; regulates the activity of the cardiovascular system. Chopped leaves of the plant are Spazmolotica and sedative. Casmin that is made of the plant has an antiplatelet and anticogliant effect. Lomaherpan cream applied to the face rush has antivirus effect. Contains combined extracts and essential oil and exists in the composition of "Dormiplant", "Novo-Passit", "Persen", "Nervoflukus", "Qastrovit", "Enerqotonik", "Altaleks" drugs. In addition, the plant is widely used in the intestines diskensia, cholecystitis, cholangitis, kidney stone, urine tracts diseases, angina, and climacteric syndromes (2, pp. 138-144). affecting Antibacterial is used in frunculose, herpes, stomatitis and parodontoses.. The young leaves are used in cookery. The smell of lemon essential oil is used in parfumery.

Foeniculum vulgare Mill. biennial herbaceous plant, and up to $2 \mathrm{~m}$ in height, rounded bushy, branching from the upper body. The leaves are alternate, lower leaves stalky, numerous, featherlike-divided, linear, while the upper leaves are almost settled. Flowers are small, yellow, petal 5 was formed intricate floral group. Hanging fruit length is $10 \mathrm{~mm}$, the width is equal to $4 \mathrm{~mm}$.

Chemical composition: fruits contains 6\% essential oil, the main ingredient anetol (up to $60 \%$ ) fenxon, pinene, metilxavikol and $18 \%$ fatty oils. $0.6 \%$ of organic substances, mineral substances are considered to be $0.5 \%$. Ripe fruit is concidered qualytive raw material.

Usage and intake methods: solution made of fruit is used in liver diseases, meteorism. Fennel that homeland is the Mediterranean countries has 2 types; rich with vitamins $\mathrm{A}, \mathrm{C}$ and $\mathrm{B}$ group vitamins, as well as potassium, magnesium, calcium, minerals. Fennel is used in most of the hepatitis diseases. In addition, increases appetite, facilitates digestion, is used in treatment of eye diseases, develops metobolism, temperature reduction, eliminates the lack of blood, cardiovascular diseases, diseases of the throat, helps to eliminate stress. In addition, the respiratory tract, rheumatism, antibacterial and antikanserogen effect are known.

Anethum graveolens $\mathrm{L}$. annual grass plant, is equal to the height of $40-120 \mathrm{~cm}$. The main root is subtle, frigale, and branching. Its stem is straight or slightly bent, branching, elongated light green and green, thin layered. The leaves are alternate, was feathered, length $30 \mathrm{~cm}, 4-25 \mathrm{~cm}$ in width. Lower leaves, stalk, $4-12 \mathrm{~cm}$ in length, the middle and upper leaves of the short stalk sedentary. Flowers are complex, multirawed, flower umbrella is $7-30 \mathrm{~cm}$ in diameter. Flowers are small, bisexual, five membered, yellow, petal, narrow, wrapped up in peak. The fruits hanging, loose ellipsed, 3-7 $\mathrm{mm}$ in length, width 1,5$4 \mathrm{~mm}$, yellowish-brown color. The aboveground part of the plant smells sweet-spicy aromatic and delicious. In June-August blossoms, the fruit grows in August-September (3, pp. 103-105).

Chemical composition: Contains essential oil (2-4\%), and its main component karvon (40-60\%), limonene (19-40\%), fillandren, dihidrokarbon and other terpenoids. Furanoxromons is part of the fruits. Seeds contains $20 \%$ fatty oils, seed $0,56-1,5 \%$ essential oil containing a large amount (16\%), carbon-containing substances, plenty of vitamins (C, B1, B2, PP, P), carotenoids, potassium salts, calcium, phosphorus, iron, folic acid and flavonoids (quercetin, kempferol) are available.

Usage and taking methods: is spazmolotic and has precipitation ability, diuretic effect. Together with raw fennel is a very valuable as precipitation and effective medicines against metobolism. The leaves are used in hypochromic anemia. Containing ascorbic acid, carotene and iron are. In hypertension is used as a diuretic. Medicine gained from fennel fruit increases the secretion of the pancreas, spazmolotic, 
decreases cough, diuretic, and increasing the function of the activity of the intestine and antibacterial pharmaceutical plant. Furanoxromons in dill expand coranar and peripheral veins. Dill has A, C and B group vitamins, as well as iron, potassium, calcium, phosphorus, rich in salts. In addition to the food and cosmetics industries essential oil of dill is widely used in medicine. Has a calming effect, regulates the activity of the cardiovascular system. Eliminates insomnia; is very useful against liver diseases; the best pain killer; accelerates the healing of wounds. Eliminates cough. Reduce blood cholesterol; is applied in Gall bladder disease prevention.

Rosmarinus officinalis L. is evergreen strong branching shrub, height is 0,5-1,5 $\mathrm{m}$; yellowishbrown body is cracked; young stems are, thick and white haired. The leaves settled, face to face, the edges are linear, the length is $3-4 \mathrm{~cm}$, shiny dark green upper side and lower side with sharp ridges. Brushed flowers are collected; receptacle is bellformed and twoparted. Flower carolla is darkblue, two lipped, upper lip is deep twoparted, lower lip is the freckled and has 2 narrow lines. Fruit cocsists of 4 smooth, rounded-egg receptacles.

Chemical composition: leaves include $\alpha$-pinene, essential oil (30\%), camphene (20\%), borneol (10\%), cineole $(10 \%)$, borneolaseat (up 7\%) and the other terpenoids. In addition, the composition of the diterpenoids (carnizol, carnozid acid), vaccine ingredients, triterpene acids (oleic and ursol), found in rosemary and pirrolidin alkaloid groups (4, pp 189195).

Usage and acceptance procedure: as a Medicinal plant rosemary leaves are used in diseases, such as gall bladder (especially compromising the expulsion), anti-inflammatory, as increasing weakness, cardiac neurosis, neuritis and cold, gynecological practice and menstration disorders. Fresh leaves and stem is used to inhalate in common cold, balm is put on the pain of rheumatism and for applying radiculite; includes European and British pharmacopoeia. Rosemary has a good effect on memory. In modern medicine, rosemary are also used as a light sedative during migraine and digestive problems. A group of co-workers from the University of Northumbria in a test conducted on the effects of rosemary oil. In British Psychological Society conference, Dr. Mark Moss as a result of the benefits of research confirmed aroma of this plant effects on short-term memory, as accelerator. Rosemary oil has a spazmolotic, antiseptic and anti-inflammatory impact during inhalation and extrenal applying. Extracts and essential oil-containing medicines combined canefron N, Marathon, Pulmeks, Tussidermil N are example; Antihistamine effective.

Thymus serpyllum L. evergreen, branching, small shrub plant with thin woody stem. Straight flowering stems is in the height of $2-15 \mathrm{~cm}$. The leaves are faced with a short stalk, ellipsed edges, a mediumsized. The average length of the leaves on the stems is $5-10 \mathrm{~mm}$, width $1,5-3,5 \mathrm{~mm}$. The head has a group of flowers. Flowers are narrow bel formed, receptacle is haired.

Chemical composition: Contains Timola (50\%), carvacrol, terpinin, terpineol, singiberin, borneol, vaccine ingredients, flavonoids, resin, ursol and oleic acids; $18 \%$ containes in the extractive and dry substances, organic and mineral substances is not more than $1 \%$.

Usage and taking methods: contains bitter substances so has an appetive effect, has healing properties in gastrointestinal, liver, pancreas disease. As infusing, baking and extracts is used in inflammation of the upper respiratory diseases, tuberculosis, diphtheria and bronchial asthma. "Pertussin"'s the main component is thyme. It is taken as extrenal procedure in muscles and peripheral nerve system diseases, is regarded as an aromatic bath; in acute and chronic respiratory diseases brewing extracts, bronchial asthma and tuberculosis are applied. As a bactericidal drugs is used against anti-convulsive, firming, soothing, healing, anti-worm medicine. Good melliferous plant. At the same time is used in parfumery. In Bulgarian medicine is used for bronchial asthma, peptic ulcer disease, loss of appetite, flatulence and diarrea. Rheumatism, angina, nerves and skin diseases is recommended by adopting in the form of a bath. In German medicine, flowers are used as aromatic baths in cough. In French medicine, it is recommended in spazmolotic, helmint against the renewal of epithelial tissues, burns from acids ( $10 \mathrm{~g}$ per one liter of water); children Rheumatism: $2 \mathrm{ml}$ of the plant extract, $1 \mathrm{~g}$ of rosemary, lavender $1 \mathrm{~g}$, soda 350.0 . is made in the form of bath. In Austrian medicine infusing is used against gastritis, flatulence, cramps. is infused $5 \mathrm{gr}$ $250 \mathrm{ml}$ in Solid state. The daily dose is $500 \mathrm{ml}$. In Polish medicine is used against bactericidal, antiinflammatory, kidney, liver, neuralgia, rheumatic fever, bronchitis and bronchial asthma. It is possible to take in cough and stomach discomfort as the following mixture. Plant is used as pain killer in radiculitis and nevritits and extract "pertussin" is used with bronchitis and other respiratory diseases. Balm is used in therapeutic bath, skin diseases $(6, \mathrm{pp}$. 825-827).

- $20 \mathrm{~g}$ thyme flowers, $10 \mathrm{~g}$ of pepper, $10 \mathrm{~g}$ to $10 \mathrm{~g}$ of spring adonis yarrow, $10 \mathrm{~g}$ cumin, plantain $10 \mathrm{~g}, 10 \mathrm{~g}$ of a mixture of 2 teaspoons sehciceyi $250 \mathrm{ml} 3$ cups of water for 10 minutes every other day should be taken by infusing. For external usage: 1-2 tablespoons of the plant for 2 cups of boiling water are used by infusing.

Folk Medicine: A strong inflammatory (has Timola), anti-convulsive, sedative, analgesic drug, has the 
effect of healing and vermifugal; is used in Hypertension, atherosclerosis, neuralgia, radiculitis, Thyrotoxicosis (goiter), neurosis and hysteria diseases; is appointed in Vermifugal, diaphoretic, as a matter neuralgia, gastrointestinal pain. Brewing and solution of the leaves are used in heart disease, constipation, liver diseases. In addition, it is considered useful to implement in diseases such as hypertension and atherosclerosis.

Mentha piperita $\mathrm{L}$. planted in a cultural way, is a perennial herbaceous plant, $30-100 \mathrm{~cm}$ in height. Straight body, branching, fourtongued, deciduous, sometimes bare or has short hair. horizontal branching thin, knotted, it has a fringed root system. Leaves cross, facing a short stalk, oblong-egg, taped, importantly Heart Shaped, dark green upper side and lower side is light green. Flowers are small, with the body lying at the receptacle flowers and flower spiky group meeting. Receptacle is tubular, 5 toothed and purple. Petal is irregular, dark-purple color.

Chemical composition: leaves contain $2.7 \%$ of essential oils, flowers up to $6 \%$, while the body is $0.3 \%$. ; includes Carotene (40mg\%), ursol and oleic acids, triterpens, puleqon, phytoncids, hesperidin, flavonoids and betaine. Leaves contain menthol. Organic ingredients, $1 \%$, while mineral substances containing $1 \%$, Special aroma causes smell of essential oils, in particular due to the fact mentolun. This has local anesthesia, srazmolotic, analgesic and antiseptic effect, with the reflector in Caronar expands blood vessels. Olimetin (Olimetinum), enatin (Enatinum), pine (Anestezol), validol, Zelenin drops and other medicines containing menthol. Solution is used as a sedative by 1:20. freshly harvested leaves are used to make preparations such as valocardin and milocardin, carvalol (1, p. 132138).

Usage and intake method: Mint is spazmolotic, analgesic, antiseptic, bile and yelqovucu property. Stimulating the cardiovascular system, to be analgesic hypertension, angina, rheumatism and is very effective in the treatment of atherosclerosis. It is recommended for the treatment of Upper respiratory tract, bronchial asthma and bronchiectasis. In bile duct and intestine Diskenition has a good effect; Improves digestion and appetite; is applied in Gastritis, ulcers, colitis, enterkolit, flatulence, breathlessness, vomiting and diarrhea diseases; was included in herbal tea in thr treatment of Gall stones, hepatitis and cholecystitis diseases. Taking mint continuously in strengthens and soothing hysteria, fatigue, migraine, along with a positive impact on disease, but also has a diuretic effect. Since the majority of delicious blends of aromatic and medicinal plants are included. Bathrooms are applied external. This application can be in form of drop, mikustura, tablets (validol) and pencil form. Since the composition of the menthol leaves are used in angina, gastric and intestinal pains. Mentolun valerianla validol blend, a mixture of paraffin is used in the form of a pencil in migren. In addition, the leaves increase appetite, are applied in shortness of breath and vomiting. German doctors stomachaches, meteorizm, Austrian and Bulgarian doctors leaves brewing, baking and oil gastro-intestinal spasm, meteorism, diarrhea, shortness of breath and vomiting bile, liver diseases (stones, jaundice, kidney pains) and advise determining headaches. They also need to be taken baths; is used as a component of tea as perspitation, food, as well as confectionery, and cosmetics industries, in the preparation of toothpaste and powders. the leaf extract and tea is used in the increasing the acidity of stomach, gall bladder. Essential oil is prepared, freshining, medicinal tea, flavored water, juice and so on. Infusing is assigned to patients for kidneys, joints, urinary tract salt, stone, as well as gastrointestinal regulate blood circulation and reduces pain. Mint pepper oil which is famous for its unique flavor and freshness is widely used in confectionery factory, perfumes, cosmetics, toothpaste, as well as in the preparation of various kinds scented soaps. There are a number of modern medicine preparations are made of pepper mint. So, while oil is part of "Zelenin drops", "validol", "Valokordin as" part of the heart drugs. Ore (tincture) is the best medicine to relieve the pain in the stomach. In particular, liver diseases - hepatitis, liver enlargement, anemia is considered indispensable medicinal plants.

- 2 tablespoons plant, 2 cups boiling water by infusing (Thermos) 3 times a day, every time it needs to drink 30 minutes before a meal (The daily dose).

- Peppermint oil (Oleum Menthae piperitae). containing $50 \%$ of the menthol is used in dental practice, leather rush and mialgiyada. Is considered a contraindication to hypotension.

Matricaria recutita L. annual grass plant, whether you have a weak body, height $60 \mathrm{~cm}$, base branching, thickset-sırıml, the upper part of the leaves. The leaves are alternate, $2-5 \mathrm{~cm}$ in length, sit down, line, and tapered $15-20 \mathrm{~mm}$ of flowers, the flowers are white, tongued, including a built yellow tubular. Receptacle is bare and longand edge of flowers is curved.

Chemical composition: composition of flowers is $0.8 \%$ essential oil, terpens, valuable substance matrix, matricarin and xamazulin. In addition, the composition of the flavonoids, polysaccharides, carotenoids and ascorbic acid were found. $1 \%$ of organic matter and mineral substances does not exceed $0.5 \%$.

Usage and intake procedure: has sedative effect on the nerve system, anti-inflammatory, antiseptic, blood stopping, analgesic, perspirative, bile, astringent, softening and antiallergic feature; is appointed for nerve system disorders, neurosis, hysteria, chorea, epilepsy, neuralgia, trigeminal 
inflammation and dismenorrea. Chamomile is used in diseases of the respiratory system, such as a weak purgative cough substance; are usedgastrointestinal tract gastritis, peptic ulcer disease, entercolit, nonspecific colitis, cholecystitis, hepatitis, intestinal diseases and flatulence. is included in many mixtures Kidney, urine tract and diatese. is appointed for angina, stomatitis and peridontit, eczema, burns frunculyiose.

- 2 cups boiling water 2-3 tablespoons flowers by infusing ( in Thermos), should be taken 3 times a day.

- When applying external 2 cups boiling water 4-6 tablespoons flowers will be evaporated. Flowers are antispasmodic and antiallergic. It is taken as part of the solution, and mixtures. As part of the essential substance of the romazulan dezodorasion an inflammatory and mouthwash, to compress, is designated for the treatment of enteritis and colites; has poor antiseptic and astringent effect. Raw material must be dried in open, green and good ventilated places or $35-40^{\circ} \mathrm{C}$ temperatures, drying cupboard. Chamomile is a very powerful antiseptic, with anti germ and virus features; has very good effect in the use of chamomile infusing in Angina, pharyngitis.

- A tablespoon of dried flowers Matricaria recutita brewed in a cup of boiling water, filtered and used as a gargle several times during the day. the brew chamomile is used antritis, sinusitis and wash the nasal cavity and chamomile oil (1-2 drops in the path of the nose) is more effective. Chamomile has also very good calming effect on the human nerve system. For this reason, a very soothing chamomile medicines intended for children and adults. A cup of chamomile tea before going to bed at night (a cup of boiling water + a teaspoon chamomile) is made by adding a teaspoon of honey. In addition, this tea helps to reduce high fever. Chamomile brew increases the ability to defend the liver, bladder and urinary tract infections in the best effect; is widely used in cosmetology. Brew cleanses the skin, fights inflammation, makes hair more shiny, strong and vibrant, and helps dundruff.

Inul helenium L. straight-bodied, herbaceous perennials, plant height of 1-2 meters. Large leaves are alternate, oblong-ellipssed edges toothed unequal. Flowers are like a big basket, equality body is at its peak. Outside flowers are tongued, golden-green, while the middle ones are tubular. Roots are brownish-gray color, short, small, length is $20 \mathrm{~cm}$, width up to $2-3 \mathrm{~cm}$.

Chemical composition: roots and rhizomatous root include essential oil composition, alontolacton (1$3 \%$ ), and $44 \%$ inulin triterpenoid lacton saponinpsevdoinulin, inulenin, resin, vaccination, $\beta$ sitositerin triterpene saponin, a significant palmitic, vinegar and benzoic acids. content of the leaves $3 \%$ essential oil, $\mathrm{C}$ and $\mathrm{E}$ vitamins, vaccinations items
$(9.32 \%)$, lacton $(1.19 \%)$, fumarin, vinegar and propanoic acids, complex Galen, lacton, inulin and has alkaloids. Hippocrates, the father of medicine valued the plant.

- needed to take in by infusing $20 \mathrm{~g}$ root in $200 \mathrm{ml}$ of water in 30 minutes 3 times a day.

Usage and intake methods: used for bronchitis, pneumonia, asthma, tuberculosis and diphtheria disease is being used. inflammatory quality depending on the nature of the liver and biliary tract, gastritis, colitis, diuretic effect are determined diseases. Plantain is used in the case of diarrhea, chronic enterkolit, constipation, loss of appetite. Rhizomatous roots is helpful for bronchitis, tracheitis, pulmonary tuberculosis, asthma, diseases. The quality of medicinal plants cough stopping and desinfectioning. Solution is considered endemic goitre as well as gastritis, ulcers, radiculitis, and duodenal ulcer disease. High antihelmint (especially ascarids) is effective drug plant. In particular, 1: 100 and 1: 1000 concentration chasing parasites. And rhizomatous roots preperation is applied for (crushed, briquette), respiratory diseases, especially in the composition of mixtures. The preparation called alanton has a very good effect in a 012 gr dose 3 times a day after meals peptic ulcer disease within 68 weeks.

- 2 teaspoons adding a cup of boiled water stored in thermos. 1/3 cup 3 times a day, 20-40 minutes before a meal should be taken. In order to infuse a tablespoon of the root with 2 cups of water must be warmed over the fire within 10-15 minutes; is advisable to take 1-2 tablespoons every other hour. In acute renal diseases and pregnancy, adoption of this plant is prohibited. Skin diseases (leysmaniose, eczema, skin rush) filtered through the roots and put on skin in hot condition. Tibetan medicine is considered plantain valuable. In Bulgarian medicine roots infusing is used in palpitations, headaches, epilepsy and diphtheria. The composition of the ancient recipe for the treatment of skin diseases is as follows:

- $180 \mathrm{~g}$ to $360 \mathrm{~g}$ of valerian root is boiled in water and mixed with $120 \mathrm{~g}$ of bacon and butter. In Rheumatism is determined in togather with the other plant.

- 2 tablespoons water in a cup of valerian root infused in 30 minutes, 10 minutes, cooled, 0.5 cup 23 times a day is taken an hour before a meal.

- 2 teaspoons crushed valerian root boiled 0.5 cups of cold water stored in 8 hours 30 minutes 4 times a day before meals are taken.

- $20 \mathrm{~g}$ per $100 \mathrm{~g}$ of $70 \%$ solution valerian root of alcohol stored in 8-10 days. 20 drops are taken 3 times a day 20 minutes before meals.

Must not be taken during pregnancy. Because premature birth may occur.

Taraxacum officinale Wigg. - Drug dandelion 
Synonyms: Pharmacy dandelion, dandelion, pergu, milkgrass, hairy, milkweed

Botanical characteristics: perennial herbaceous plants, and pulpy short and small branches, whether straight rooted. Leaf umbrella is bare, with the length of $10-25 \mathrm{~cm}$ deep boatformed-feathered, gradually narrowing, of the long-winged stalk. flower group length is $30 \mathrm{~cm}$, cylindrical, hollow, bare edges, like a soft, hairy spider web. Flowers bisexual, tongueshaped and light yellow in color, large basket accrue, with a diameter of $5 \mathrm{~cm}$.

Chemical composition: The roots contain bitter glycosides (taraksatsin and taraksasepin), triterpene compounds, $24 \%$ inulin, resin and fatty oils. in Veterenary is applied for gastrointestinal diseases.

Usage and intake procedure: roots of bitter substances appetizers, natural liver diseases and has bile remover effect; is concidered most popular source of medicinal plants with artichoke in liver disases. According to medical studies, these plants improve the function of the liver. In particular, liver diseases such as hepatitis B, dandelion is used. At the same time, helps to remove excess accumulated nicotine and alcohol in gallbladder from body.

- a tablespoon Dandelion root is added $200 \mathrm{ml}$ (one cup) of boiling water is infused on boiling water bath for 15 minutes and cooled to room temperature, filtered. 3-4 times a day, every time $1 / 3$ cup is taken 15 minutes before meal. It is used in Cholesistitd, hepatoxolesists, anasitqastrits, oroniki constipation, during obesity and atherosclerosis, as well as used as a means to improve appetite and digestion increases.

Artemisia absinthium L. perennial herbaceous plants, whether it is up to $2 \mathrm{~m}$ in height. Roots diversified, short, vertical and woody. All of the above-ground parts of the yellowish-white in color, covered with dense hair. There is a distinctive, sharp smell of wormwood. Stems numerous, thickset, the upper side of leaves broomed-branching. Lower leaves are usually wilt during flowering. Umbrellas and lower stalk have leaves, the length of $20 \mathrm{~cm}$, egg, elongated, elegant taped, was completesided, 1-5 mm in length. Stem leaves are alternate. Summit leaves are settled, and completesided. Tubular yellow flowers, like a balloon, is up to $4 \mathrm{~mm}$ in diameter. After floerting becames bare, leaves on the outside are linear, the inner side is ellipsoid. Flowers form a large group of flowers.

The chemical composition of grass and flowers within the $2 \%$ essential oil, the main ingredient tuyon, tuyol, fellandren, seksiviterpen absintin lactones, anabsintin, artabsin, bitter taste of raw ingredients, which are flavonoids and vaccinations. Composition of plant is vaccine ingredients, artemizin flavonoidi, organic acids, carotenoids and ascorbic acid. Inulin contains the root structure.
Extracts are widely used in animals, such as antilelminit [Ibadullayeva et al., 2015].

Usage and intake method: The rule adopted by the use of vegetable (whole and splited) and flowers quality appetizers, such as the gastrointestinal system booster is used in brewing and the composition of mixtures. As useful as raw materials in brewing and baking. Scientific medicine studied the bitter substance contained mainly increases appetite, energy is restored. It can be compared with a very bitter chinin. Bitter substance contained in wormwood (absintin) and other items are useful gastrointestinal, in particular, stimulates the pancreas function. Wormwood enhances the activity of the central nerve and hematopoietic system, asthenia, fatigue, anemia, and epilepsy, the treatment of diseases guarantees. Since the composition of ingredients stops cough, are used in the prophylaxis antipyretics and malaria, and treatment of influenza and acute respiratory diseases. Particularly successfully are appointed hipersection accompanied by diseases of the stomach. At the same time committed is very effective in the treatment of diseases acute and chronic hepatitis B and $\mathrm{C}$ virus, cholecystitis. Wormwood as well as for the treatment of diseases of the liver and gall bladder tracts are included to mixtures. Compostion full of diuretic and anti-inflammatory ingredients. The drug is used for prophylaxis and treatment of diseases such as flatulence, dismenorreya, kidney kidney stone and vermifugal. In recent years, wormwood is applied to intestinal diseases. Infusing of wormwood as a drug is used to compress externally, to eliminate worms such as ascarids.

- 0.5 teaspoon plant infused in $250 \mathrm{ml}$ boiling water, cooling for 10 minutes 3 times a day for 1.5 hours before or after a meal, must ne taken in (The daily dose). The course of treatment is 2-3 weeks. During pregnancy, the setting is considered a contraindication. Increases the liver's ability to defend.

Menyanthes trifoliata $\mathrm{L}$. buckbean is perennial herbaceous plants, and wetland plant. Root is long and reptiles. peak of the roots is slightly lifted, consisting of 3 parts of the junction leaves a long stalk. Stalk's length is $20 \mathrm{~cm}$, the base has expanded and the sheath of a dice. Completesided leaves are bare, or ellipssed or eggshaped. Axis length is $30 \mathrm{~cm}$ in spring flowers. Matte-pink flowers are several $\mathrm{cm}$ in diameter. heavy brush is $3-7 \mathrm{~cm}$ in length.

Chemical composition: the composition of the leaves consists of bitter glycosides (loganin and sverezil), vaccine ingredients, flavonoids, organic and mineral substances; is used for gastrointestinal tract disorders in cattle and calves.

Usage and intake methods: Contains bitter substances used during weakness in the gastrointestinal system, 
in particular, chronic gastritis, gastric secrector, loss of appetite, bile and diuretic, the general malaise; is Especially effective in gall bladder stone disease.

- 2 tablespoons of dry leaves infused in 0.5 liters of boiled water (The daily dose) (Thermos), 20-40 minutes before a meal is taken 2-3 times a day; is included bitter compoitions. Leaves (whole and split) are quality appetizers, the best bitter solution is body firming. Water buckbean is used in improving digestion, migraine, hepatitis and other liver diseases, - A glass of water is added a tablespoon of dried leaves and infused for 15 minutes. Is taken 30 minutes before a meal, a glass a day

- 2 teaspoons of the leaves is added on a cold glass of water, mixed with a tablespoon every eighth hour and taken 3 times a day (time to hepatitis and cholecystitis).

\section{References}

1. Abu Ali IbnSinaThe Canon of Medicine. / Translation Yu.S.Zavadovskogo and S. Mirzayev, t. II, Tashkent, 1982

2. Alekperli F.U. A thousand and one secret of the East. Volume 1. Baku, Tural, 2001505 P.

3. Chalilov Ch. Ethnographyofworldnations. Baku, 1999.

4. Chursin G.F.1929. A programmme for ethnographic data collecting. It's compiled with reference to a life of the Caucasian peoples. Pub/house for Publ. Survey and Study. Azerbaijan

5. Cotton C.M. 1996. Ethnobotany: Principles and application. Chichester-New-York-Brislane-TorontoSingapore: John Willey and Sons.

6. Geibullaev G.A. By ethnogenesis of Azerbaijanis. Volume 1. Baku: 1991, pp. 216-274

7. Damirov I.A., Prilipco L.I., Shukurov D.Z., Kerimov U.B. 1988. Herbs of Azerbaijan. Baku: 319.

8. Ethnobotany: Integrating Biology and Traditional Knowledge. Missouri Botanical Garden. St. Louis, MO. November 7-8, 2008.

9. Ibadullayeva S.J. \&Jafarli I. A. Essential oil and aromatherapy. Baku, "ELM" . 2007, 150p.

10. Ibadullayeva S., Alakberov R. 2013. Medicinal plants (Ethnobotany andPhytotherapy), Baku- Elm, 2013, 370 p.

11. Ibadullayeva S., Mamedova S.E., Sultanova Z.R., Movsumova N.V., Jafarli I.A.2010. Medicinal plants of Azerbaijan flora used in the treatment of certain diseases//
International Journal of Pharmacy and Pharmacology Vol. 4(5). ISSN 1996-0816 @ Academic Journals, p-s 545548

12. Ibadullayeva S.J., Gahramanova N.J., Shahmuradova M.J. 2012. Use of wild plants at dermatosis (skin desaeses): Ethnobotany/ Journal of Applied Pharmaceutical Science Volume2 Issue: 8, august. DOL: 10.7324

13. Ibadullayeva S.J., Shahmuradova M.J., Mustafayev A.B. 2013. Protection of some rare and critically threatened medicinal plants in the Azerbaijan flora/ Journal of Biology and Life Science. ISSN 2157-6076, vol. $4 \mathrm{~N} 1$. P.145-152. http://dx.doi.org/10.5296/jbls.v4i1.2827

14. Ibaddullayeva S.,Gahramanova M.,Gasymov H., Zulfigarova P. 2015. Etnobiological and phytotherapeutic analysis of medicinal herbs of Azerbaijan flora used at cardiovascular diseases treatment. Global Journal of Biology, Agriculture \& Health Sciences. Vol 1.N-1, pp.

15. Ibadullayeva S.J., S.H.Maharramov, L.A.Novruzova,Agayeva E.Z.2015. Study Of Treatment Advantage Of Medicinal Herbs With Antihelmintic Effect AgainstNeoascariasis/ International Journal of Agriculture Innovations and Research. Vol.3, Issue 3, (Online) 23191473

16. Ford R.I. Ethnobotany: Historical Diversity and Synthesis // The Nature and Status of Ethnobotany. 2nd edition. Ed. R.I. Ford. Annbbor, 1994. p. 33-49.

17. Grossheym A.A. 1936. Analysis of flora of Caucasus. / Works of Bot. Inst. of the Azerb. Branch of the Acad. of Sciences. of the USSR, Baku.

18. Guber R. (2001) La Etnografia. Metodo, campo y reflexividad. Norma, Bogota.

19. Krylova I.Y., Shreter A.I. 1971. Methodical directions on resource study of the wild herbs. М: ВИЛАР, 21p-s.

20. NuhAfandi. Qarabadin, From Collection of Handwriting Institute

21. Martin G.J. 2001. Etnobotany. Manual de methods. Nordan - Comunidad. Montevideo,Uruguay.

22. Prilipko L.I. 1965. Herbal resources of natural \& economical areas of the Azerbaijan SSR. Baku. 134.

23. Sokolov S.Y. 2000. Phytotherapy and phytopharmacology. M:Medical Inform. Agency, 971.

24. Turova A.D., Sapojnikova E.N. 1984. Herbs of the USSR and their use. M:Medicine, 230.

25. The Azerbaijan flora. 1950-1961. Volumes I-VIII. Baku:

26. Zayko L.N., Pimenova M.E., Maslikov V.U. 2007. Review of the method and results on study of herbs of Russia (ВИЛАР). Transactions of the Int. Scientific and Practical Conference. Present-day problems of phytodesign. Belgorod, 148-157. 